\title{
An algorithm to calculate feasible operating conditions of electrical network, given overhead conductor temperature and sag constraints
}

\author{
Yekaterina Popova ${ }^{1, *}$ Oleg Voitov and Lyudmila Semenova ${ }^{1}$ \\ ${ }^{1}$ Energy Systems Institute of Siberian Branch of the Russian Academy of Sciences, Department of Electric Power Systems , 664033 \\ Lermontov str., 130, Irkutsk, Russia
}

\begin{abstract}
The paper presents an algorithm to calculate feasible steady-state conditions of an electrical network. A distinctive feature of the calculation is the consideration of constraints on the temperature of bare conductor and the clearance of a controlled span of overhead line. This consideration is based on forming and solving an equation of conductor heat balance to calculate the conductor temperature depending on the current flowing through the conductor and environmental factors, including the actual values of air pressure and air temperature. The paper presents the results of numerical calculations performed for individual overhead lines and for a test 16-node scheme of electrical network. The results illustrate the algorithm performance and the importance of considering the above constraints
\end{abstract}

\section{Introduction}

The bulk of present-day algorithms and software designed to calculate steady-state and feasible operating conditions of electrical networks do not consider the actual temperature conditions of overhead lines. Such parameters of conductors as active resistance and conductor sag (or clearance) are frequently determined in these conditions considering only the air temperature, and ignoring the effect of many other environmental factors and current load of conductors [1].

The overwhelming majority of domestic and foreign software developed to calculate the feasible load flow (except for the one proposed in this paper) does not take into account mechanical parameters of conductors: the sag and length of the conductor (or clearance). This leads to an incorrect estimation of a capability of transmitting additional power along individual conductors and in the spans of the electrical network.

Meanwhile, at the up-to-date level of hardware and software development, mathematical modeling of an electrical network suggests and allows increasing the accuracy of mathematical description of both the parameters of the electrical network components and the means for control of their operation. The issues of modeling overhead lines whose parameters are complex functions of environment state parameters and electrical network operating parameters are very important. As is known, the design of overhead lines involves consideration of a wide spectrum of factors affecting the line parameters, which enables the safety conditions for people and machinery to be met, and the reliability of the overhead line operation to be provided. However, eventually, both the parameters of components and the design conditions vary. This leads to the necessity of monitoring the mechanical parameters of the overhead lines (sag, clearance) [2,3] that are based on both their real measurements and numeric calculations performed during the intervals between planned measurements.

In this paper, we propose calculating the feasible power flow, considering both electrical (nodal voltage, currents) and geometric (sag, clearance) parameters of lines. This can be done by considering and solving the equations of the conductor heat balance and state, that make it possible to determine the conductor temperature, to specify the value of thermal current rating and to check if the rated sag and clearance values are met. The sag and clearance should be calculated for particular controlled spans, because considering all the spans leads to an excessive increase in the dimensionality of the power flow problem. For example, for a $500-\mathrm{kV}$ overhead line $300 \mathrm{~km}$ long with a $500-\mathrm{m}$ span, the number of spans will be about 600 . For each overhead line, we suggest considering only the so-called controlled spans, for which it is sensible to monitor the state of clearances, for example, in the sites, where the overhead lines of different voltage levels intersect, or have very long spans, etc. To take into account the controlled spans in the calculation of power flow, it is necessary to additionally specify sag heights and physical-mechanical parameters of conductors. It is also necessary to introduce additional nodes that will split the initial line into sections, whose total length is equal to the line length.

The paper is arranged as follows. Section 1 addresses a general algorithm to calculate power flow in the electrical network, considering environmental factors (air temperature and pressure, wind velocity and

\footnotetext{
* Corresponding author: elen@isem.irk.ru
} 
direction, solar radiation) that make it possible to determine the temperature of overhead bare conductor. Section 2 briefly describes an algorithm to calculate the conductor temperature, considering environmental factors $[4,5]$. Section 3 presents an algorithm to calculate the feasible power flow, considering inequality constraints on the load flow variables [6]. Section 4 discusses an algorithm to calculate the current carrying capacity in lines, considering the sag and clearance constraints in a controlled span [7]. Section 5 provides an analysis of the numerical calculation results obtained with the SDO-7 software for individual overhead lines and for a case study [8].

\section{An algorithm to calculate feasible power flow in electrical network}

The algorithm contains the following stages.

A. Calculate feasible power flow of the electrical network, temperature, sag and clearance in the controlled spans. If the values for the controlled parameters are feasible, the algorithm terminates. Otherwise, we go to step B.

B. Calculate the thermal current ratings at which the conductor temperature corresponds to a standard value and the constraint on the clearance in each controlled span is met. Return to step A and repeat calculations, until the specified accuracy of determining the thermal current ratings is reached.

Let us address each stage of the algorithm in more detail.

\section{Calculation of overhead conductor temperature}

Based on algebraic transformations of the heat-balance equation in a quadratic form, given in the standard documentation [9], we form a sixth degree polynomial for each $i-j$ line [5]:

$$
f\left(T_{\text {con }}, U_{i}, U_{j}, z_{i j}, d_{c o n}, T_{\text {air }}, Q_{r}, Q_{c}, Q_{\text {rad }}, v\right)=0 .
$$

After (1) is solved, the Newton method is used to find the conductor temperature $T_{c o n}$ for the actual values of: nodal voltages $U_{i}, U_{j}$, magnitude of line complex impedance $z_{i j}$, conductor diameter $d_{c o n}$, air temperature $T_{\text {air }}$, solar radiation power $Q_{r}$, convective $Q_{c}$ and radiation $Q_{\text {rad }}$ heat transfer coefficients, and wind velocity $v$.

The convective heat transfer coefficient of the "traditional" heat-balance equation (1) is determined for normal environmental factors: an air pressure of $760 \mathrm{~mm}$ $\mathrm{Hg}$, and an air temperature of $0^{\circ} \mathrm{C}$. For other values of the air temperature and pressure, the convective heat transfer coefficient is determined by the expressions [5] obtained by transforming the initial criteria equations of convective heat transfer [9] that characterize the conditions for free convection (at $v \leq 1.2 \mathrm{~km} / \mathrm{s}$ )

$$
Q_{c 1}=0.39 \cdot d_{\text {con }}^{0.75} \cdot\left(T_{\text {con }}-T_{\text {air }}\right)^{0.3} \cdot P_{\text {air }}^{0.5} / T_{\text {air }}^{0.75} .
$$

and forced convection (at $v \leq 1.2 \mathrm{~km} / \mathrm{s}$ )

$$
Q_{c 2}=0.661 \cdot \sqrt{d_{c o n} \cdot v \cdot P_{\text {air }} / T_{\text {air }}} .
$$

The specified expressions (2), (3) in their explicit form contain the actual environmental factors to be taken into account.

\section{Calculation of feasible power flow}

We state and solve the non-linear programming problem of the form [6]

$$
\begin{array}{r}
W(Z, D)=0, \\
Z_{\text {min }} \leq Z \leq Z_{\text {max }}, \\
F(Z) \leq F_{\text {max }},
\end{array}
$$

where $W$ is a vector-function of nodal active and reactive power imbalances; $Z$ is the state variable vector including complex numbers of nodal voltages and transformation ratio; $D$ is the vector of nodal loads; $F$ is the vector of functional variables including active and reactive power, power flows, and currents along the lines; $Z_{\text {min }}, Z_{\text {max }}, F_{\text {max }}$ are the vectors of minimum and maximum values of variables.

When solving the matrix equation (4) by the NewtonRaphson method for each controlled $i-j$ line, we consider the relationship between the longitudinal resistances $r_{i j}$ and the magnitude of current in the line [4]. For this purpose, at the point of solution to polynomial (1), which is an implicit function $z_{i j}\left(U_{i}, U_{j}\right)$, we find derivatives $\partial r_{i j} / \partial U_{i}$ and $\partial r_{i j} / \partial U_{j}$ used to create the elements of the Jacobian matrix row of the form $\partial w_{k} / \partial r_{i j} \cdot \partial r_{i j} / \partial U_{i, j}$, where $k$ is the row number. Solution to problem (4)-(6) contains, in particular, the values of conductor temperature for each controlled line that correspond to the design conditions, i.e. the nodal loads and environmental factors.

\section{Consideration of constraints on the clearance of the controlled span and conductor temperature}

After the conductor temperature $T_{c o n}$ is calculated for each controlled span, we build the conductor state equation [10] of the form

$$
\begin{gathered}
\sigma_{n}-\frac{E \cdot \gamma_{n}^{2} \cdot l_{c o n}^{3}}{24 \cdot \sigma_{n}^{2} \cdot l}=\sigma_{m}-\frac{E \cdot \gamma_{m}^{2} \cdot l_{c o n}^{3}}{24 \cdot \sigma_{m}^{2} \cdot l}- \\
-\alpha \cdot E \cdot\left(T_{\text {con_n }}-T_{\text {con_m } m}\right),
\end{gathered}
$$

where $\alpha$ is the coefficient of linear thermal expansion for the conductor material, $\mathrm{C}^{-1} ; E$ is the conductor 
elasticity modulus, $\mathrm{Pa}$, whose values are assumed according to the data of reference books [11]; $l_{c o n}, l$ are the conductor length and the controlled span length, $\mathrm{m}$. In equation (7), the values of parameters with the subscript $n$ correspond to the current design conditions, and those with the subscript $m$ correspond to the case, where the conductor is under the maximum permissible tension $\sigma_{m}=\sigma_{p}$, and only its own weight $\gamma_{m}=\gamma_{1}$ affects it. The conductor temperature $T_{\text {con } m}$ is assumed equal to the lowest air temperature of $-40^{\circ} \mathrm{C}$, and the assumed wind velocity is $v \leq 1.2 \mathrm{~m} / \mathrm{s}$.

By solving equation (7), we find the tension in the conductor material $\sigma_{n}$ that is used [10] to calculate the length of a big equivalent span $l_{e q}$ and the conductor sag $f_{i j}$ in the controlled span $i-j$ (Fig.1).

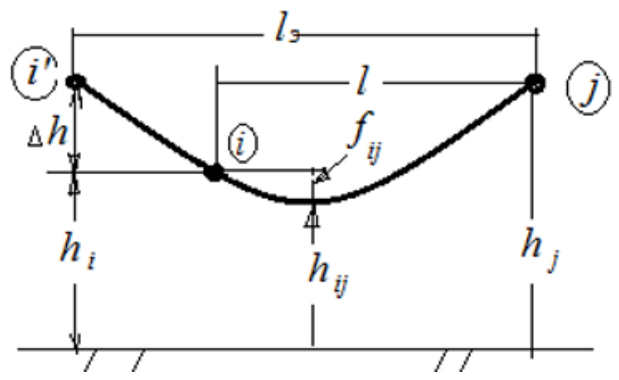

Fig. 1. A sag in the overhead line controlled span

$$
\begin{gathered}
\Delta h=\left|h_{i}-h_{j}\right|, \\
l_{e q}=l+\frac{2 \cdot \sigma_{n} \cdot \Delta h}{\gamma_{n} \cdot l}, \\
f_{e q}=\frac{\gamma_{n} \cdot l_{e q}^{2}}{8 \cdot \sigma_{n}}+\frac{\gamma_{n}^{3} \cdot l_{e q}^{4}}{384 \cdot \sigma_{n}^{3}}, \\
f_{i j}=f_{e q}-\Delta h,
\end{gathered}
$$

where $h_{i}, h_{j}$ are the heights of the conductor suspension in the controlled span of the overhead line; $f_{e q}$ is a sag of the big equivalent span.

The clearance in the controlled span is calculated by the following expression

$$
h_{i j, \min }=\min \left(h_{i}, h_{j}\right)-f_{i j} .
$$

If the temperature constraints

$$
T_{\text {con_ij }} \leq T_{\text {con_max }}
$$

and/or the clearance constraints

$$
h_{i j} \geq h_{i j, \min } \text {, }
$$

are not met, where $T_{\text {con_max }}$ is the maximum allowable conductor temperature assumed equal to $70^{\circ} \mathrm{C}$ according to [11]; $h_{i j, \min }$ is the minimum clearance in the controlled span, we calculate the thermal current ratings of the line, at which constraints (13)-(14) are met.
For this purpose, when condition (13) is not met, we form the equation of conductor heat balance of the form

$$
\begin{gathered}
f\left(T_{\text {con_max }}, I_{i j_{-} \text {max }}, z_{i j}, d_{\text {con }}, T_{\text {air }},\right. \\
\left.Q_{r}, Q_{c}, Q_{\text {rad }}, v\right)=0,
\end{gathered}
$$

and by solving (15) we find the value of the thermal current ratings $I_{i j \_ \text {max }}$ for the known temperature value $T_{\text {con_max }}$.

When condition (14) is not met, we use expression (16) to determine the maximum permissible sag $f_{i j \_}$in the span, at which the clearance condition is met:

$$
f_{i j \_p}=\min \left(h_{i}, h_{j}\right)-h_{i j \_ \text {min }} .
$$

Further, from expression (10) for the maximum permissible sag value $f_{i j \_p}$, we find the maximum permissible tension $\sigma_{n \_}$, and from the equation of state (7), considering $\sigma_{n \_}$, we determine the conductor temperature, at which condition (14) is met. Then, we solve the conductor heat-balance equation (15) to determine the thermal current rating.

\section{Algorithm testing results}

The proposed algorithm to calculate feasible power flow was tested both for individual overhead lines with conductors from various manufacturers and for the test 16-node scheme.

A. We investigated the effect of the actual air parameters (air pressure and temperature, both considered in the convective heat transfer coefficient in the conductor heat-balance equation (1)), on the overhead conductor parameters (their temperature and resistance per unit length) for the conductor AC-120/27 (Table 1).

The calculations allowed for the wind velocity $v<1.2 \mathrm{~m} / \mathrm{s}$ at its direction perpendicular to the conductor. The radiation heat transfer coefficient was assumed equal to $Q_{\text {rad }}=0$. The values of conductor current varied in a range of $I=\left\lfloor 100 \div I_{i j_{-} \max }\right\rfloor \mathrm{A}$, where $I_{i j_{-} \text {max }}=375 \mathrm{~A}$ is the value of thermal current rating for the AC-120/27 conductor.

We considered the air parameters: $T_{\text {air } i}=20^{\circ} \mathrm{C}$, $P_{\text {air } i}=(710 ; 640) \mathrm{mm} \mathrm{Hg}$, characteristic of Irkutsk (Irkutsk Region) and of Orlik Settlement (Okinsky District, Republic of Buryatia [12]).

The following notations were used in Table 1: $\Delta T=\left|T_{\text {con }}^{n-n o r m}-T_{\text {con }}^{\text {norm }}\right| \quad$ and $\delta r=\left(r_{O\left(T_{c o n}\right)}^{n-n o r m}-r_{0\left(T_{c o n}\right)}^{n o r m}\right) \cdot 100 \% / r_{0\left(T_{c o n}\right)}^{n-n o r m} \quad$ are the absolute and relative errors in determining the conductor temperature and resistance per unit length. The errors 
occur due to considering normalized (instead of actual) air parameters in the heat-balance equation; $T_{c o n}^{\text {norm }}$, $r_{0\left(T_{c o n}\right)}^{\text {norm }}$ are the conductor temperature and resistance per unit length at normalized parameters $P_{\text {air }}, T_{\text {air }}$;
$T_{\text {con }}^{n \text {-norm }}, r_{0\left(T_{c o n}\right)}^{n \text {-norm }}$ are the same conductor parameters at the current air parameters $P_{\text {air } i}, T_{\text {air } i}$.

Table 1. Relationship between the temperature and resistance per unit length of the AC-120/27 conductor and the air parameters in the heat-balance equation at $v<1.2 \mathrm{~m} / \mathrm{s}$.

\begin{tabular}{|c|c|c|c|c|c|c|c|c|c|c|}
\hline \multirow[t]{2}{*}{ I, A } & $\begin{array}{l}T_{\text {con }}, \\
{ }^{\circ} \mathrm{C}\end{array}$ & $\begin{array}{l}\left.r_{O\left(T_{\text {con }}\right)}\right) \\
\mathrm{Ohm} / \mathrm{km}\end{array}$ & $\begin{array}{l}T_{\text {con }}, \\
{ }^{\circ} \mathrm{C}\end{array}$ & $\begin{array}{l}r_{0\left(T_{c o n}\right)} \\
\mathrm{Ohm} / \mathrm{km}\end{array}$ & $\begin{array}{l}T_{\text {con }}, \\
{ }^{\circ} \mathrm{C}\end{array}$ & $\begin{array}{l}r_{0\left(T_{\text {con }}\right)}, \\
\mathrm{Ohm} / \mathrm{km}\end{array}$ & $\begin{array}{l}\Delta T, \\
{ }^{\circ} \mathrm{C}\end{array}$ & $\begin{array}{c}\delta r \\
\%\end{array}$ & $\begin{array}{l}\Delta T \\
{ }^{\circ} \mathrm{C}\end{array}$ & $\begin{array}{c}\delta r \\
\%\end{array}$ \\
\hline & \multicolumn{2}{|c|}{$\begin{array}{c}P_{\text {air }}=760 \mathrm{~mm} \mathrm{Hg}, \\
T_{\text {air }}=0^{0} \mathrm{C}\end{array}$} & \multicolumn{2}{|c|}{$\begin{array}{c}P_{\text {air } i}=710 \mathrm{~mm} \mathrm{Hg} \\
T_{\text {air } i}=20^{\circ} \mathrm{C}\end{array}$} & \multicolumn{2}{|c|}{$\begin{array}{c}P_{\text {air } i}=640 \mathrm{~mm} \mathrm{Hg}, \\
T_{\text {air } i}=20^{\circ} \mathrm{C}\end{array}$} & \multicolumn{2}{|c|}{$\begin{array}{c}P_{\text {airi }}=710 \mathrm{~mm} \mathrm{Hg}, \\
T_{\text {air } i}=20^{\circ} \mathrm{C}\end{array}$} & \multicolumn{2}{|c|}{$\begin{array}{c}P_{\text {air } i}=640 \mathrm{~mm} \mathrm{Hg}, \\
T_{\text {air } i}=20^{\circ} \mathrm{C}\end{array}$} \\
\hline 100 & 26,63 & 0,2586 & 27,10 & 0,2591 & 27,39 & 0,2593 & 0,47 & 0,19 & 0,76 & 0,27 \\
\hline 200 & 40,02 & 0,2721 & 41,50 & 0,2736 & 42,43 & 0,2745 & 1,48 & 0,55 & 2,41 & 0,87 \\
\hline 300 & 59,41 & 0,2916 & 62,48 & 0,2947 & 64,44 & 0,2967 & 3,07 & 1,1 & 5,03 & 1,72 \\
\hline 375 & 78,32 & 0,3107 & 83,11 & 0,3155 & 86,17 & 0,3186 & 4,79 & 1,5 & 7,85 & 2,48 \\
\hline
\end{tabular}

As is evidenced by an analysis of the calculations (similar to the above) for the AC-120/27 conductor parameters at different combinations of $P_{\text {air } i}, T_{\text {airi }}$ in the heat-balance equation, the maximum improvement in the conductor parameters is achieved at: $P_{\text {air } i}=640$ $\mathrm{mm} \mathrm{Hg}, T_{\text {air } i}=40^{\circ} \mathrm{C}$, and is $\delta r=3,35 \%$ at $v<1.2$ $\mathrm{m} / \mathrm{s}$.

B. We investigated the effect of considering the constraints on conductor sag (or the clearance) in the controlled span of the overhead line (14) on the calculation results of feasible power flow on the example of a test electrical network.
Table 2 presents the parameters for the investigated scheme, where we used the following notations: $N_{\text {nod }}$, $N_{\text {OHL }}, N$ are number of nodes, overhead lines and controlled spans; $l_{\mathrm{OHL}}$ are the length of overhead lines; $P_{\text {gen,sum }}, P_{l d, \text { sum }}$, are the total active power of generation and load of the electrical network scheme; $U_{\text {nom }}$ are the rated voltage levels. The wind velocity in power flow calculation was assumed to equal $v<1.2 \mathrm{~m} / \mathrm{s}$, the wind direction was perpendicular to the conductor.

Table 2. Parameters of the test scheme

\begin{tabular}{|c|c|c|c|c|c|c|c|}
\hline$N_{\text {nod }}$ & $N_{\text {OHL }}$ & $N$ & $l_{\text {OHL }}, \mathrm{km}$ & $l, \mathrm{~m}$ & $P_{\text {gen,sum }}, \mathrm{MW}$ & $P_{l d, \text { sum }}, \mathrm{MW}$ & $U_{\text {nom }}, \mathrm{kB}$ \\
\hline 16 & 16 & 2 & $50-200$ & $300-500$ & 2164.3 & 2100 & $500-20$ \\
\hline
\end{tabular}

In the power flow calculations, additionally, the air parameters in the convective heat transfer coefficient of the heat balance equations were varied (2).

Table 3 demonstrates the influence of air temperature and pressure on the thermal current ratings calculated for the AC-240/32 conductor of the overhead line in an electrical network.

Table 3. Dependence of the AC-240/32 conductor thermal current ratings on the air parameters in the heat-balance equation at $v<1.2 \mathrm{~m} / \mathrm{s}$, and $T_{\text {con }}=60^{\circ} \mathrm{C}$

\begin{tabular}{|c|c|c|c|c|}
\hline \multirow{2}{*}{$P_{\text {air }}, \mathrm{mm} \mathrm{Hg}$} & \multicolumn{4}{|c|}{$I_{\text {ij_max }}, \mathrm{A}$} \\
\cline { 2 - 5 } & $T_{\text {air }}=-20^{0} \mathrm{C}$ & $T_{\text {air }}=0^{0} \mathrm{C}$ & $T_{\text {air }}=20^{0} \mathrm{C}$ & $T_{\text {air }}=40^{0} \mathrm{C}$ \\
\hline 660 & 856,82 & 708,03 & 547,95 & 359,79 \\
\hline 700 & 867,19 & 716,19 & 553,85 & 363,27 \\
\hline 760 & 882 & 727,85 & 562,29 & 368,25 \\
\hline
\end{tabular}


air parameter variation in the convective heat transfer coefficient.

Table 4 shows the comparison of the thermal current rating values for three overhead lines equipped with AC-
240/32, AC-300/64, and AC-600/72 conductors. These values were obtained from the calculation of the feasible power flow based on the above-mentioned method and from the standard documentation [9].

Table 4. Comparison of the conductor thermal current ratings calculated using the 1987 method and the method proposed in the paper (SDO) at $P_{\text {air }}=760 \mathrm{~mm} \mathrm{Hg}, T_{\text {air }}=0^{\circ} \mathrm{C}$.

\begin{tabular}{|c|c|c|c|c|c|c|c|c|c|}
\hline \multirow{3}{*}{$\begin{array}{c}T_{c o n}, \\
{ }^{\circ} \mathrm{C}\end{array}$} & \multicolumn{2}{|c|}{$I_{i j \_ \text {max }}, \mathrm{A}$} & \multirow[t]{2}{*}{$\begin{array}{c}\delta I, \\
\%\end{array}$} & \multicolumn{2}{|c|}{$I_{i j \_ \text {max }}, \mathrm{A}$} & \multirow[t]{2}{*}{$\begin{array}{c}\delta I, \\
\%\end{array}$} & \multicolumn{2}{|c|}{$I_{i j \_ \text {max }}, \mathrm{A}$} & \multirow[t]{2}{*}{$\begin{array}{c}\delta I, \\
\%\end{array}$} \\
\hline & $\begin{array}{c}1987 \\
\text { method }\end{array}$ & $\begin{array}{c}\text { SDO } \\
\text { method }\end{array}$ & & $\begin{array}{c}1987 \\
\text { method }\end{array}$ & $\begin{array}{l}\text { SDO } \\
\text { method }\end{array}$ & & $\begin{array}{c}1987 \\
\text { method }\end{array}$ & $\begin{array}{c}\text { SDO } \\
\text { method }\end{array}$ & \\
\hline & \multicolumn{3}{|c|}{ AC-240/32 } & \multicolumn{3}{|c|}{ AC-300/64 } & \multicolumn{3}{|c|}{ AC-600/72 } \\
\hline 20 & 390 & 389,2 & 0,2 & 450 & 451,7 & 0,4 & 715 & 713,1 & 0,3 \\
\hline 40 & 580 & 580,9 & 0,2 & 670 & 674 & 0,6 & 1065 & 1063 & 0,2 \\
\hline 60 & 730 & 727,8 & 0,3 & 845 & 844,5 & 0,1 & 1340 & 1332 & 0,6 \\
\hline 80 & 845 & 849,7 & 0,6 & 985 & 985,9 & 0,1 & 1565 & 1555,2 & 0,6 \\
\hline
\end{tabular}

Table 4 demonstrates that at comparable calculation conditions (rated air parameters $P_{\text {air }}=760 \mathrm{~mm} \mathrm{Hg}$, $T_{\text {air }}=0^{0} C$ that are included in coefficient (2)), the results of calculations differ by less than $1 \%$, which is within the round-off error of calculation results.
Table 5 presents the feasible power flow calculated considering the constraints on temperature (13) and clearance (14) in two controlled spans of the overhead line.

Table 5. Feasible power flow calculated considering constraint on clearance in the spans at $P_{\text {air }}=760 \mathrm{~mm} \mathrm{Hg}$.

\begin{tabular}{|c|c|c|c|c|c|c|c|c|c|c|}
\hline $\begin{array}{l}\text { Span } \\
\text { nodes }\end{array}$ & $\begin{array}{l}\text { Conduct } \\
\text { or type }\end{array}$ & $\begin{array}{c}l_{e q}, \\
\mathrm{~m}\end{array}$ & $\begin{array}{c}T_{\text {con_max }}, \\
{ }^{0} C\end{array}$ & $\stackrel{\mathrm{Ij} \_ \text {max }}{\mathrm{A}}$, & $\begin{array}{l}h_{i}, \\
\mathrm{~m}\end{array}$ & $\begin{array}{c}h_{j}, \\
\mathrm{~m}\end{array}$ & $\begin{array}{c}h_{i j, \text { min }}, \\
\mathrm{m}\end{array}$ & $\begin{array}{c}h_{i j}, \\
\mathrm{~m}\end{array}$ & $\begin{array}{c}f_{i j \_}, \\
\mathrm{m}\end{array}$ & Notes \\
\hline $2-5$ & AC-400 & 470 & 70 & 825 & 15 & 7 & 3 & 3 & 12 & $I_{i j_{-} \max }=0$ \\
\hline $10-20$ & AC-240 & 602 & 70 & 605 & 15 & 8 & 7 & 7 & 8 & $I_{i{ }_{-} \max }=0$ \\
\hline $2-5$ & AC-400 & 300 & 45,3 & 523,1 & 14 & 14 & 7 & 7 & 7 & \\
\hline $10-20$ & AC-240 & 300 & 63,9 & 558,6 & 14 & 14 & 7 & 7 & 7 & \\
\hline
\end{tabular}

As seen from two upper lines in Table 5, when the specified mechanical clearances in spans $l_{e q}, h_{i}, h_{j}$, $h_{i j}$, do not correspond to a physical sense (i.e. to the recommended span length and suspension height at standard supports for a given voltage class) [11], the calculated thermal current rating is equal to zero. This is because the calculated conductor sag is much larger than that allowable one under the set clearances, and the calculated allowable conductor temperature is much lower than the air temperature. In such a situation, the feasibility of the operating conditions can be provided by refusing to consider the constraints on mechanical clearances, and instead, specifying the rated values of temperature $T_{\text {con_max }}$ and the conductor current $I_{i j \_ \text {max }}$ in spans.

With specified clearances in the same spans that correspond to a physical sense (Table 5, bottom lines), the calculated allowable conductor temperature is lower than the rated value $T_{\text {con } \max }=70^{\circ} \mathrm{C}$. In this case, the transfer capability of the controlled spans should be reduced by $37 \%$ and $8 \%$, to provide feasible operating conditions and minimum clearance $h_{i j, \text { min }}$, respectively.

\section{Conclusion}

1. Our study indicates that correction of the convective heat transfer coefficient in the equation of conductor heat-balance by considering the current values of air pressure and temperature rather than the rated ones makes it possible to expand the list of considered environmental factors, and to increase the accuracy of modeling overhead line and operation of the entire electrical network.

2. It is important to improve the algorithm to calculate the feasible power flow of the electrical network by considering an additional inequality constraint imposed on the minimum clearance (or allowable sag) within the 
controlled span because it enables the calculation results to be considerably corrected when making decisions about additional current load of the lines.

3. The developed algorithm demonstrated its performance and an agreement between the calculation results for the thermal current rating of conductors and its values from standard documentation in the comparable cases.

\section{References}

1. E.V. Popova, Improvement in the algorithms to calculate power flow in electric power systems considering the current temperature conditions of overhead lines: PhD dissertation (Irkutsk, P. 172, 2017).

2. B.I. Mekhanoshin, V.A. Shkaptsov, Elektro 6, 33 (2006).

3. A.V. Samarin, D.B. Rygalin, A.A. Shklyayev, Natural and Technical Sciences 1,2 (2012).

4. O.N. Voitov, E.V. Popova, Electricity 9, 24 (2010).
5. E.V. Popova, Power Energy Through the Eyes of Youth: Proceedings of 3rd International ScientificTechnical Conf. Collected papers, Vol. 1, 351 (Ekaterinburg: UrFU, 2012).

6. N.A. Murashko, Yu.A. Okhorzin, L.A. Krumm, et al., Analysis and Control of Steady States of Power Systems (Nauka, Novosibirsk, 1987).

7. K.P. Kryukov, B.P. Novgorodtsev, Design and mechanical calculation of power transmission lines (Energiya, Leningrad, 1979).

8. Compliance Certificate No. ROSS RU.SP20.N00008 "The SDO software to analyze and optimize steady states, and assess electric power losses in electrical networks" - Certification System of GOST R Gosstandart of Russia. Valid through: 31 Jan 2009 31 Jan 2012.

9. A technique to calculate thermal current ratings for operating transmission lines (Soyuztekhenergo, Moscow, 1987).

10. E.F. Makarov, Reference book on 0.4-36 $\kappa V$ electric networks, Vol. 1 (Papyrus Pro, Moscow, 1999,).

11. http://www.gismeteo.ru <http://www.gismeteo.ru> (accessed 15 Apr 2018). 